\title{
Sacral Osteotomy Combined With Lumbopelvic Distraction Osteosynthesis in the Treatment of Malunion or Nonunion of Vertically Displaced Pelvic Fractures
}

\section{Yangxing Luo}

Tongji Hospital of Tongji Medical College of Huazhong University of Science and Technology

Li He

Tongji Hospital of Tongji Medical College of Huazhong University of Science and Technology

Yue Li

Tongji Hospital of Tongji Medical College of Huazhong University of Science and Technology

Jie Xie

Tongji Hospital of Tongji Medical College of Huazhong University of Science and Technology

\section{Song Gong}

Tongji Hospital of Tongji Medical College of Huazhong University of Science and Technology

Qian Zhang

Tongji Hospital of Tongji Medical College of Huazhong University of Science and Technology

Enzhi Yin

Tongji Hospital of Tongji Medical College of Huazhong University of Science and Technology

Meiqi Gu

Tongji Hospital of Tongji Medical College of Huazhong University of Science and Technology

Chengla Yi ( $\nabla$ chenglayi@163.com )

Tongji Hospital of Tongji Medical College of Huazhong University of Science and Technology

\section{Research article}

Keywords: sacral osteotomy, lumbopelvic distraction osteosynthesis, pelvic fracture, malunion, nonunion

Posted Date: November 1st, 2021

DOI: https://doi.org/10.21203/rs.3.rs-988502/v1

License: (우 (i) This work is licensed under a Creative Commons Attribution 4.0 International License. Read Full License 


\section{Abstract}

Background Malunion or nonunion of vertically displaced pelvic fractures resulting in lower limb length discrepancies, claudication, and pain. There have been few previous reports of this type of corrective surgery of the old pelvis. We present a new surgical technique of sacral osteotomy combined with lumbopelvic distraction osteosynthesis (LPDO) in the treatment of malunion and nonunion of vertically displaced pelvic fractures and report on its short-term clinical results.

Methods We retrospectively reviewed nine patients (five males and four females) with malunion or nonunion of vertically displaced pelvic fractures treated with sacral osteotomy and LPDO from April 2015 to January 2020. The age ranged from 14 to 45 years (average, 30.7 years). The time from injury to deformity correction surgery ranged from 3 months to 5 years (average, 12.8 months). The vertical displacement of a unilateral pelvis was $3.0-4.5 \mathrm{~cm}$ (average, $3.80 \mathrm{~cm}$ ). According to the AO/OTA classification at initial pelvic fracture, eight cases were type C1.3 and one case were type C3.3. Sacral osteotomy and LPDO were used in all nine patients. The degree of unilateral pelvic reduction was assessed postoperatively based on measurements from the anteroposterior (AP) X-ray. The Majeed score and pain visual analog scale (VAS) score were used to assess the therapeutic effect of the patients during follow-up.

Results In all nine patients, postoperative AP X-ray showed correction displacement of 1.7-3.9 cm (average, $3.20 \mathrm{~cm}$ ). All the patients were followed up for 6 to 36 months (average, 12.7 months). At the last follow-up, the Majeed score of pelvic fracture increased from an average of 53.9 points (30-84 points) preoperatively to 87.0 points (72-94 points), and the VAS score for pain decreased from an average of 6.0 points (4-8 points) preoperatively to 1.2 points (0-3 points). None of the patients had complications, such as infection, implant broken, screw loosening, iatrogenic nerve, or blood vessel injury.

Conclusion Sacral osteotomy combined with LPDO for the treatment of pelvic malunion or nonunion caused by sacral fracture can correct significantly vertical displacement of a unilateral pelvis, prolong limb length, and reconstruct the stability of a pelvic ring, leading to good clinical results.

\section{Introduction}

Sacral fractures with vertical displacement are type $\mathrm{C}$ pelvic fractures, which are often caused by high-energy injuries and are frequently associated with multiple injuries [1]. In the early stage, the treatment of life-threatening bleeding and associated injuries is predominant, and the reduction of pelvic fractures is absent. When the patients are stable both physiologically and hemodynamically, the fresh fracture becomes old. Due to the complex and high risk of surgery for old pelvic fractures, sophisticated surgical techniques and related equipment are required. Insufficient techniques and a lack of related equipment lead to pelvic fractures that do not involve surgical reduction and rigid internal fixation, which eventually cause malunion or nonunion $[2,3]$. Malunion or nonunion with significant vertical displacement of a unilateral pelvis results in the unbalanced transmission of axial forces from the spine to the lower limbs, causing lower limb length discrepancies, gait instability, posture problems (sitting and standing imbalance), pain in the posterior and anterior pelvic ring, and aesthetic defects [3-6].

To restore the normal morphology of the pelvis, osteotomy of anterior and posterior pelvic rings is often required to correct the vertical displacement of a unilateral pelvis [3]. Reduction and fixation are also indispensable after osteotomy. Kach and Trentz et al. [7] reported a technique to treat the vertical displacement of posterior pelvic ring injuries, which they called lumbopelvic distraction osteosynthesis (LPDO). It uses a pedicle fixation system to distract longitudinally between L4, L5, and the iliac crest and is especially applicable to sacral fractures with significant vertical displacement. LPDO combines with transverse fixation (sacroiliac screw or transiliac/transsacral plate) to form triangular osteosynthesis which has been proven biomechanically to be the most stable fixation of the posterior pelvic ring [2]. This construct provides multiplanar stability.

For the reasons above, we used sacral osteotomy combined with LPDO to treat nine patients with pelvic malunion or nonunion originating from sacral fractures from April 2015 to January 2020. In this study, we retrospectively reviewed these data to (1) present the surgical technique of sacral osteotomy and (2) analyze clinical effect of this treatment from the clinical and radiological aspects.

\section{Patients And Materials}




\section{Demographic data}

Patients consented to have their case data collected and used for publication.

Inclusion criteria: (1) with nonunion or malunion of type C pelvic fractures treated from April 2015 to January 2020; (2) posterior pelvic ring fracture was sacral fracture; (3) anteroposterior (AP) X-ray showed vertical displacement of a unilateral pelvis greater than $2 \mathrm{~cm}$; (4) lumbosacral pain when walking or standing, excluding other causes, confirmed to be caused by sacral nonunion; (5) fractures for over 3 months; (6) age under 60 years.

Exclusion criteria: (1) severe internal medical diseases that could not tolerate surgery; (2) severe mental illness that could not cooperate with surgical management; (3) incomplete medical records; and (4) follow-up time less than 6 months.

Based on the above criteria, a total of nine cases (five males and four females) were included. The age ranged from 14 to 45 years with an average of 30.7 years. According to the causes of injury, there were six cases of motor vehicle accident injury and three cases of fall injury. According to the early combined injury, there were two cases of cerebral trauma, one case of thoracic injury, five cases of abdominal injury, three cases of limb fractures, one case of third-degree burn wound in the left inguinal region, and one case of sacral plexus injury. At the time of fracture, according to the AO/OTA classification, there were eight cases in type C1.3 and one case in type C3.3 (the left sacrum fracture had no displacement, and the right sacrum fracture was vertical displacement and nonunion); according to the Denis classification, there was one case in Denis I and eight cases in Denis II. All nine patients had pubic ramus fractures. The time from injury to surgery ranged from 3 months to 5 years, with an average of 12.8 months. The basic data of these patients are presented in Table 1. 
Table 1

Basic data of patients

\begin{tabular}{|c|c|c|c|c|c|c|c|c|}
\hline $\begin{array}{l}\text { Case } \\
\text { NO. }\end{array}$ & Age(years) & Gender & Cause & $\begin{array}{l}\text { AO/OTA } \\
\text { Classification }\end{array}$ & $\begin{array}{l}\text { Denis } \\
\text { Classification }\end{array}$ & $\begin{array}{l}\text { Preoperative } \\
\text { neurological } \\
\text { deficit }\end{array}$ & Associated lesions & $\begin{array}{l}\text { Delay } \\
\text { to } \\
\text { surgery }\end{array}$ \\
\hline 1 & 29 & $\mathrm{~F}$ & Fall & C1.3 & II & & $\begin{array}{l}\text { Thoracic injury, } \\
\text { abdominal injury }\end{array}$ & 2 years \\
\hline 2 & 44 & $M$ & $\begin{array}{l}\text { Motor } \\
\text { vehicle } \\
\text { accidents }\end{array}$ & C1.3 & II & & $\begin{array}{l}\text { Right femoral } \\
\text { fracture }\end{array}$ & 5 years \\
\hline 3 & 32 & $M$ & $\begin{array}{l}\text { Motor } \\
\text { vehicle } \\
\text { accidents }\end{array}$ & C1.3 & II & & $\begin{array}{l}\text { Cerebral injury, } \\
\text { right humerus } \\
\text { fracture }\end{array}$ & $\begin{array}{l}3 \\
\text { months }\end{array}$ \\
\hline 4 & 19 & $\mathrm{~F}$ & Fall & C1.3 & II & Yes & $\begin{array}{l}\text { Right femur } \\
\text { fracture }\end{array}$ & $\begin{array}{l}8 \\
\text { months }\end{array}$ \\
\hline 5 & 45 & $\mathrm{~F}$ & $\begin{array}{l}\text { Motor } \\
\text { vehicle } \\
\text { accidents }\end{array}$ & C1.3 & I & & Abdominal injury & $\begin{array}{l}3.5 \\
\text { months }\end{array}$ \\
\hline 6 & 29 & $\mathrm{~F}$ & $\begin{array}{l}\text { Motor } \\
\text { vehicle } \\
\text { accidents }\end{array}$ & C1.3 & II & & $\begin{array}{l}\text { Abdominal injury, } \\
\text { left ulnar fracture }\end{array}$ & $\begin{array}{l}3.5 \\
\text { months }\end{array}$ \\
\hline 7 & 31 & $M$ & $\begin{array}{l}\text { Motor } \\
\text { vehicle } \\
\text { accidents }\end{array}$ & C1.3 & II & & Cerebral injury & $\begin{array}{l}4 \\
\text { months }\end{array}$ \\
\hline 8 & 14 & M & Fall & C1.3 & II & & Abdominal injury & $\begin{array}{l}3 \\
\text { months }\end{array}$ \\
\hline 9 & 33 & M & $\begin{array}{l}\text { Motor } \\
\text { vehicle } \\
\text { accidents }\end{array}$ & C3.3 & II & & $\begin{array}{l}\text { Abdominal injury, } \\
\text { third- } \\
\text { degree burn wound } \\
\text { in the left inguinal } \\
\text { region }\end{array}$ & $\begin{array}{l}6 \\
\text { months }\end{array}$ \\
\hline
\end{tabular}

\section{Preoperative preparation}

The patient's neurological function was assessed for the associated loss of lower limb motor function and skin sensation before operation. Activities of daily living were scored according to the Majeed score from five perspectives: pain, standing, sitting, sexual intercourse, and work performance $[8,9]$. The degree of pain was scored according to the pain visual analog scale (VAS). Laboratory indexes were detected to rule out infection, including white blood cell (WBC) count, erythrocyte sedimentation rate (ESR), and C-reactive protein (CRP). The image data were used to assess the degree of fracture displacement and callus formation, including AP X-ray, inlet X-ray, outlet X-ray, and three-dimensional computed tomography (3D-CT). The degree of vertical displacement of a unilateral pelvis was assessed by the gap between the vertical lines, which pass through acetabular apexes on both sides and are perpendicular to the central axis of the sacrum on the anteroposterior AP X-ray of the pelvis. Fasting, water deprivation, skin preparation, and indwelling catheterization were required before surgery. Enema was performed the night before surgery and the morning of surgery. Sufficient plasma and concentrated red blood cells were also indispensable. An autologous blood transfusion device should be prepared before surgery.

\section{Operative Procedure}

Pelvic malunion or nonunion requires multistage surgery. The sequence, either supine-prone-supine or prone-supine, was individualized in each case. In the supine-prone-supine sequence, after performing the superior and inferior pubic ramus osteotomy of the anterior pelvic ring in the supine position, the anterior surgical incision was closed temporarily. Subsequently, 
after the patient was turned to the prone position, sacral osteotomy, reduction, and internal fixation were performed, and the incision was closed; then, the patient was turned back to the supine position, and the anterior surgical incision was reopened. After reduction and fixation of pubic rami, the surgical incision was sutured. In the prone-supine sequence, after performing the sacral osteotomy, reduction, and fixation in the prone position, the incision was sutured; then, turning to the supine position, the anterior pelvic ring scar was released, and the end of the fracture was refreshed. After the anterior pelvic ring was reduced and fixed, the anterior surgical incision was closed.

The surgical approach for the anterior pelvic ring was the Stoppa approach. Under general anesthesia, the patient was positioned supine on a radiolucent operating table, and a midline incision was made $2 \mathrm{~cm}$ above the pubic tubercle to expose the pubic rami. The obturator fascia was dissected. The obturator nerves and vessels were exposed. A 2.0-mm K-wire was used as the guide needle, which was inserted from the superior pubic ramus to the inferior pubic ramus medial to the obturator neurovascular bundle. After determining the position of the guide needle under fluoroscopy, the superior and inferior pubic rami were cut along the guide needle (Fig. 1A, B). Complete disconnection of the superior and inferior pubic rami was confirmed with fluoroscopy, and then the surgical incision was closed temporarily.

Sacral osteotomy of a posterior pelvic ring was performed in the prone position. A longitudinal incision was made at a position 2 $\mathrm{cm}$ lateral to the L4-S3 spinous process. The lumbodorsal fascia was dissected medially along the medial iliac crest and lateral margin of the sacrum, and the entire sacral vertebral plate and sacral foramen were exposed after lifting the sacrospinous muscle. Continuing to dissect superiorly, the L4 and L5 vertebral plates, facets, and transverse processes were exposed. The sacrotuberous ligaments were cut along the sacral margin, across which the surgeon could use the index finger to sense the hard bone cortex on the anterior surface of the sacrum. For patients with a fracture history of more than one year, both the sacrotuberous ligament and the sacrospinous ligament attached to the sacrum were cut to reduce the superior migration of a unilateral pelvis. We chose the lateral side of the sacral foramen for sacral osteotomy (Fig. 2A-C). The osteotomy line was first made by drilling with a 2.0-mm Kwire, where the osteotomy was performed. Then a vertebral plate retractor was used to separate the broken bone to ensure complete cutting and disconnection of the sacrum (Fig. 3A, B). During the osteotomy, the surgeon used the osteotome to sense the hard bone cortex on the anterior surface of the sacrum as it approached the anterior cortex of the sacrum. While the osteotome was passed through the anterior cortex of the sacrum, the surgeon touched the sacroiliac joint and anterior surface of the sacrum anteriorly with his fingers across the greater sciatic notch to ensure that the osteotome did not penetrate 2-3 mm beyond the anterior surface of the sacrum, thereby preventing injury of the presacral vessels and nerves.

After reduction of the posterior pelvic ring, LPDO was performed. The surgical instrument was the CDHTMLEGACY CMAS sacroiliac internal fixation system (WEGO, Inc., Shandong, China), which is characterized by a connection module between the posterior superior iliac spine (PSIS) screw and the connecting rod. The connection module allows the connecting rod to match the lumbosacral anatomical shape perfectly, simply by shaping in the sagittal plane without multiplanar shaping. Pedicle screws were implanted in the L4 and L5 pedicles, and PSIS screws were implanted in the PSIS. The PSIS screw size was typically $7.5 \times 80 \mathrm{~mm}$. It is important that a bone window be made on the ilium with a rongeur to allow deeper seating of the PSIS screw head, preventing the prominence of the screw head under the soft tissues. The vertical displacement of a unilateral pelvis was reduced by distracting longitudinally between the L4 pedicle screw and the connecting module, and then the posterior displacement of the unilateral pelvis was reduced by the pulling action played by turning the L5 pedicle screw cap. After reduction of the anteroposterior displacement, the locking between the connecting module and the connecting rod was loosened. Further distraction reduction was performed between the whole form of $L 4$ and $L 5$ pedicle screws together and the iliac crest screw, which prevented fixation failure caused by loosening of individual pedicle screws (Fig. 3C). After reduction was complete, the connecting module and connecting rod were relocked. Intraoperative AP, inlet, and outlet X-rays were used to confirm the reduction effect. Transverse fixation was performed with sacroiliac screws or transiliac plates. Finally, after the patient was returned to the supine position, fixation of the pubic rami was performed.

For patients with nonunion pubic ramus fractures or pubic symphysis separation, the prone-supine sequence was used (Fig. 4). All osteotomy sites were treated with autologous bone grafts.

\section{Postoperative Management}


Postoperative management included the use of prophylactic antibiotics and analgesic medication as well as prophylaxis for deep vein thrombosis. The surgical incision was drained for 48-72 hours. Patients with neurological symptoms were given trophic nerve therapy. Patients were encouraged to perform active and passive exercises of the lower limbs in bed from day 1 after surgery. Nonweight-bearing activity was started 4 weeks week after surgery. Full weight-bearing walking was allowed when the fracture healed 3 months later.

\section{Results}

The operative duration of 9 patients was 3-7 h, with an average of $4.5 \mathrm{~h}$. The intraoperative blood loss was $1300-6100 \mathrm{~mL}$, with an average of $2978 \mathrm{~mL}$. Postoperative AP X-ray showed that the correction of vertical displacement was $1.7-3.9 \mathrm{~cm}$ (average, $3.2 \mathrm{~cm}$ ). Except for one case with a postoperative residual displacement of $1.5 \mathrm{~cm}$ (preoperative vertical displacement of $3.2 \mathrm{~cm}$ ), the other eight patients with postoperative residual displacement were $0.1-0.7 \mathrm{~cm}$. These results are presented in Table 2.

Table 2

Operative data

\begin{tabular}{|c|c|c|c|c|c|}
\hline $\begin{array}{l}\text { Case } \\
\text { NO. }\end{array}$ & Postural sequence & $\begin{array}{l}\text { Operative } \\
\text { duration }\end{array}$ & $\begin{array}{l}\text { Intraoperative blood } \\
\text { loss }\end{array}$ & $\begin{array}{l}\text { Cranial } \\
\text { displacement }\end{array}$ & $\begin{array}{l}\text { Correct } \\
\text { displacement }\end{array}$ \\
\hline 1 & $\begin{array}{l}\text { Supine-prone- } \\
\text { supine }\end{array}$ & 5 hours & $3600 \mathrm{~mL}$ & $4.5 \mathrm{~cm}$ & $3.8 \mathrm{~cm}$ \\
\hline 2 & $\begin{array}{l}\text { Supine-prone- } \\
\text { supine }\end{array}$ & 5.5 hours & $3800 \mathrm{~mL}$ & $3.8 \mathrm{~cm}$ & $3.2 \mathrm{~cm}$ \\
\hline 3 & Prone- supine & 3.5 hours & $2600 \mathrm{~mL}$ & $4.1 \mathrm{~cm}$ & $3.6 \mathrm{~cm}$ \\
\hline 4 & $\begin{array}{l}\text { Supine-prone- } \\
\text { supine }\end{array}$ & 7 hours & $6100 \mathrm{~mL}$ & $3.3 \mathrm{~cm}$ & $2.8 \mathrm{~cm}$ \\
\hline 5 & $\begin{array}{l}\text { Supine-prone- } \\
\text { supine }\end{array}$ & 5 hours & $3300 \mathrm{~mL}$ & $3.9 \mathrm{~cm}$ & $3.4 \mathrm{~cm}$ \\
\hline 6 & Prone- supine & 4 hours & $1800 \mathrm{~mL}$ & $3.0 \mathrm{~cm}$ & $2.7 \mathrm{~cm}$ \\
\hline 7 & $\begin{array}{l}\text { Supine-prone- } \\
\text { supine }\end{array}$ & 4.5 hours & $2200 \mathrm{~mL}$ & $3.2 \mathrm{~cm}$ & $1.7 \mathrm{~cm}$ \\
\hline 8 & Prone- supine & 3 hours & $2100 \mathrm{~mL}$ & $4.3 \mathrm{~cm}$ & $3.7 \mathrm{~cm}$ \\
\hline 9 & Prone- supine & 3 hours & $1300 \mathrm{~mL}$ & $4.5 \mathrm{~cm}$ & $3.9 \mathrm{~cm}$ \\
\hline
\end{tabular}

One patient with a vertical displacement of $4.3 \mathrm{~cm}$ before surgery exhibited plantar numbness after surgery but without dyskinesia, which recovered after one month of neurotrophic therapy. Five cases were treated with a supine-prone-supine surgical sequence, and four cases were treated with a prone-supine sequence. Transverse fixation of the posterior ring was performed with sacroiliac screws (Fig. 4D, Fig. 5D) in three cases and transiliac plates (Fig. 6E) in six cases. The anterior pelvic ring was fixed with plates (Fig. 4D) in eight cases and an external fixator (Fig. 5E) at the upper edge of the acetabulum in one case. This case involved a third-degree burn in the left inguinal region with severe skin scars and no soft tissue release of the anterior pelvic ring was treated with an external fixator at the upper edge of the acetabulum (Fig. 5). Eight patients in our group were treated with primary fixation. In one case of pelvic malunion for 5 years, intraoperative reduction was difficult; after anterior and posterior ring osteotomy, the operative incision was temporarily closed; after one week of augmented combined traction of the femoral/pelvic area, posterior and anterior ring fixation was performed in the two-stage operation. For the two patients with fracture lines involving sacral zone II and nonunion, unilateral laminectomy was performed first, and then the nerve roots were carefully dissected; the scar and sclerotic bone at the end of the fracture were removed after nerve root exposure; subsequently, the osteotomy was performed laterally in the sacral foramen. One patient with symptoms of sacral plexus injury preoperatively was seen the S1-3 nerve roots ruptured in the operation. 
The mean follow-up time of the nine cases was 12 months (6-36 months) after the operation. Eight patients had no significant postoperative claudication and one patient had mild claudication. One patient had preoperative sacral plexus injury without recovery of ankle motor function after surgery, and ankle arthrodesis was performed 1 year later. One patient with postoperative nonunion of pubic rami was not been managed because of asymptomatic, and the remaining eight patients had healed at the osteotomy site on X-ray and CT. No iatrogenic nerve lesions were observed in any patients. All patients had no loss of reduction, and no implant breakage or loosening was found. At the last follow-up, all patients had no pain or movement pain at the osteotomy site. The Majeed score increased from an average of 54 points (30-84 points) preoperatively to 87 points (72-94 points). The VAS score for pain decreased from an average of 6.0 points (4-8 points) preoperatively to 1.2 points (0-3 points) (Table 3).

Table 3

Postoperative data

\begin{tabular}{|c|c|c|c|c|c|c|}
\hline \multirow{2}{*}{$\begin{array}{l}\text { Case } \\
\text { NO. }\end{array}$} & \multicolumn{2}{|l|}{ VAS } & \multicolumn{2}{|l|}{ Majeed score } & \multirow{2}{*}{$\begin{array}{l}\text { Follow- } \\
\text { up time }\end{array}$} & \multirow[t]{2}{*}{ Remarks } \\
\hline & Preoperative & Postoperative & Preoperative & Postoperative & & \\
\hline 1 & 5 & 1 & 84 & 94 & $\begin{array}{l}6 \\
\text { months }\end{array}$ & \\
\hline 2 & 4 & 1 & 76 & 88 & 1 year & $\begin{array}{l}\text { Right femoral nonunion with shortening } \\
\text { of } 2 \mathrm{~cm}\end{array}$ \\
\hline 3 & 7 & 2 & 41 & 91 & $\begin{array}{l}6 \\
\text { months }\end{array}$ & \\
\hline 4 & 6 & 0 & 76 & 91 & $\begin{array}{l}18 \\
\text { months }\end{array}$ & $\begin{array}{l}\text { Operated at the local hospital, } 2 \text { screws } \\
\text { on anterior ring plate were penetrated } \\
\text { the acetabulum }\end{array}$ \\
\hline 5 & 8 & 1 & 34 & 93 & 1 year & \\
\hline 6 & 7 & 0 & 30 & 89 & 3 years & \\
\hline 7 & 6 & 3 & 44 & 72 & $\begin{array}{l}6 \\
\text { months }\end{array}$ & $\begin{array}{l}\text { Operated at the local hospital, failed to } \\
\text { correct the upward displacement }\end{array}$ \\
\hline 8 & 7 & 2 & $33^{*}$ & $73^{*}$ & $\begin{array}{l}6 \\
\text { months }\end{array}$ & $\begin{array}{l}6 \mathrm{~cm} \times 11 \mathrm{~cm} \text { bedsore on } \\
\text { sacrococcygeal region }\end{array}$ \\
\hline 9 & 4 & 1 & 67 & 92 & $\begin{array}{l}6 \\
\text { months }\end{array}$ & \\
\hline \multicolumn{7}{|c|}{ VAS, pain visual analog scale score } \\
\hline
\end{tabular}

\section{Discussion}

With the promotion and popularization of early emergency treatment and reconstruction techniques for pelvic fractures, the success rate concerning early management of pelvic fractures has prominently improved, and most displaced unstable pelvic fractures can be reduced and fixed early [10]. However, some severe pelvic fractures do not qualify for early reconstruction due to the need for early rescue for life-threatening massive bleeding and associated injuries $[3,11]$. On the one hand, some doctors lack an understanding of the degree of pelvic instability and are unable to apply correct and adequate vector forces to reduce and stabilize the fractures. On the other hand, primary hospitals are limited by the available hardware and techniques, resulting in the occurrence of malunion or nonunion. In our group, one patient with type $\mathrm{C} 1.3$ pelvic fracture was not associated with obvious displacement after injury, and was given the conservative treatment of bed rest due to insufficient understanding of the instability of pelvic fracture by the surgeon. One month later, the AP X-ray revealed that the vertical displacement of a unilateral pelvis was $3.9 \mathrm{~cm}$. The patient was given a reduction of femoral skeletal traction. After the failure of traction reduction, the patient with obvious claudication came to our hospital 3.5 months later. Then, in our hospital anterior and posterior pelvic ring osteotomy, longitudinal distraction reduction of the sacrum, anterior ring plate fixation, and posterior ring LPDO were performed. Follow-up at 
8 and 15 months after surgery showed no loss of reduction (Fig. 6). The other patient had pubic ramus fractures of an anterior pelvic ring and sacral zone II fractures of a posterior pelvic ring after injury, and significant vertical displacement and symptoms of sacral plexus nerve injury were observed. Because the surgeon was unable to apply correct and adequate vector forces to reduce and stabilize the fractures and was technically limited, only the pubic rami of the anterior ring were fixed in the initial treatment; the vertical displacement of the posterior ring was not reduced, and the sacrum was not fixed. Even two screws on the anterior ring plate were mistakenly inserted into the acetabulum, resulting in claudication, hip and lumbosacral pain in patients for up to 18 months.

In recent years, due to clinical application of the pelvic reduction frame, some pelvic fractures can be treated with closed reduction and minimally invasive fixation in the early stage, with better results and a lower incidence of pelvic malunion or nonunion $[12,13]$. However, the application of this new technique has not been popularized, and some complex pelvic fractures are difficult to correct with reduction frames. Thus, pelvic malunion or nonunion still occurs.

The treatment of pelvic malunion or nonunion is challenging for surgeons because of significant intraoperative difficulties and postoperative uncertainty. Few treated cases have been reported in the literature [3]. Therefore, there is no standard treatment strategy for pelvic malunion or nonunion. However, the ultimate goal of pelvic malunion or nonunion remains the same: to restore the integrity and symmetry of the pelvic ring, carefully manage soft tissue, facilitate rapid postoperative recovery and early rehabilitation, and achieve long-term functionality of the hip joint.

Significant vertical displacement deformity is a common reason for patients coming to the hospital with pelvic malunion or nonunion. It is very difficult to correct these deformities. On the one hand, the pelvic ring fracture line has formed a callus, which needs to be converted into a fresh fracture by osteotomy. On the other hand, the severe contracture of soft tissue requires extensive release. Moreover, numerous nerves, blood vessels, and other vital structures surrounding the pelvic region further increase the difficulty of surgery and the risk of treatment.

Surgical treatment of pelvic malunion or nonunion depends on the clinical symptoms, the degree of pelvic vertical displacement, and the requirements of the patients. It is important to ascertain whether the symptoms are related to pelvic malunion or nonunion rather than to other clinical conditions. Pain from mechanical low back pain or an old neurologic injury and dysesthetic pain of neurogenic origin must be excluded [6]. Pain at the site of pelvic fractures is often caused by nonunion, and some pain is caused by nerve injury that occurs during the initial pelvic fracture, which is often difficult to eliminate [14]. We must inform patients that pelvic pain not associated with nonunion or instability is not corrected with this type of surgery [6]. Furthermore, reconstructive surgery involves the risk of many complications, including nerve injury (5.3\%), symptomatic venous thrombosis (5.0\%), pulmonary embolism (1.9\%), and deep wound infection (1.6\%) [14]. A hemipelvic displacement of $>1 \mathrm{~cm}$ or rotation of $15^{\circ}$ to $20^{\circ}$ may be not all-inclusive clinically symptomatic, but the integration of these parameters is much more likely to be clinically symptomatic, which may represent malunion [15]. Pelvic fractures with significant displacement often cause gait instability and claudication. All patients in our group had sacral fractures of a posterior pelvic ring, vertical displacement $>2 \mathrm{~cm}$ and different degrees of gait abnormalities. The patients had a strong desire for surgery to improve existing symptoms and restore equal lengths of the lower limbs. The authors deem it acceptable for a hemipelvic vertical displacement of $\leq 1 \mathrm{~cm}$ and/or rotation of $<15-20^{\circ}$ displacement. However, some studies suggest that surgical correction is indicated for rotational defects greater than $10^{\circ}$, leg length discrepancies greater than $5 \mathrm{~mm}$, and lack of reduction or imperfect facing of sacroiliac articular surfaces [14].

In the process of reconstruction, the malunion site requires osteotomy, and the scar contracture site requires release. The methods of posterior pelvic ring osteotomy include longitudinal osteotomy of the ilium and sacral osteotomy, which mainly corrects pelvic obliquity and restores lower limb length symmetry $[14,16]$. The authors believe that iliac osteotomy is mainly applied to type $B$ pelvic fractures involving the ilium and pelvic obliquity. Given that this group of patients had a sacral fracture (C1.3 or C3.3) of a posterior pelvic ring and significant vertical displacement of a unilateral pelvis, sacral osteotomy is a kind of method to better restore the shape of a pelvis.

Posterior pelvic ring fixation methods include transverse osteosynthesis, vertical osteosynthesis, and triangular osteosynthesis. Transverse osteosynthesis usually involves sacroiliac screws, sacral rods, transiliac and transsacral plates, which show poor shear resistance [2]. Vertical osteosynthesis is LPDO. LPDO with transverse osteosynthesis (triangular osteosynthesis) provides 
stability against longitudinal displacement and rotation [2,17]. LPDO was used in all patients in our group. Longitudinal distraction between the lumbar spine and the pelvis directly corrects vertical displacement of a unilateral pelvis. In addition, pelvic malunion or nonunion also needs to be combined with sacrospinous ligament and sacrotuberous ligament release.

The small number of cases in this study precludes statistical analysis and has some limitations. This study is not accurate enough for the measurement of rotational deformity of the pelvis, which will be our main research direction in the future.

\section{Conclusion}

Sacral osteotomy combined with LPDO for vertically displaced pelvic malunion or nonunion significantly improves the patient's pain, deformity, and claudication symptoms, and can be used as an effective treatment option for severe vertically displaced pelvic deformity following the sacral fracture.

\section{Abbreviations}

3D-CT: Three-dimensional computed tomography; LPDO: Lumbopelvic distraction osteosynthesis; VAS: Visual analogue scale; AP: Anteroposterior.

\section{Declarations}

\section{Acknowledgements}

We want to express our sincere appreciation for all the patients that joined this study.

\section{Funding}

No funding was provided specifically for this project.

\section{Availability of data and materials}

Please contact author for data requests.

\section{Authors' contributions}

YCL and LYX conceived and designed the study. LYX, HL, LY, XJ, GS, ZQ, YEZ and GMQ collected the data. LYX wrote the manuscript. YCL and HL read and corrected, the manuscript. All authors read and approved the final manuscript.

\section{Ethics approval and consent to participate}

The study was approved by the ethics committee of Tongji Medical College.

\section{Consent for publication}

All the patients in this study have given their informed consent for the article to be published.

\section{Competing interests}

The authors declare that they have no competing interests.

\section{References}

1. Abo-Elsoud M, Eldeeb S, Gobba M, Sadek FZ. Biplanar Posterior Pelvic Fixator for Unstable Sacral Fractures: A New Fixation Technique. J Orthop Trauma. 2018;32:e185-90.

2. Hu X, Pei F, Wang G, He J, Kong Q, Tu C. Application triangular osteosynthesis for vertical unstable sacral fractures. Eur Spine J. 2013;22:503-9. 
3. Taguchi T, Kawai S, Kaneko K, Yugue D. Surgical treatment of old pelvic fractures. International Orthopaedics. 2000;24:28-32.

4. Tripathy SK, Goyal T, Sen RK. Nonunions and malunions of the pelvis. Eur J Trauma Emerg Surg. 2015; 41:335-42.

5. Nicodemo A, Capella M, Deregibus M, Masse A. Nonunion of a sacral fracture refractory to bone grafting: internal fixation and osteogenic protein-1 (BMP-7) application. Musculoskelet Surg. 2011;95:157-61.

6. Cano-Luis P, Giraldez-Sanchez MA, Andres-Cano P. Pelvic post-traumatic asymmetry: Assessment and sequenced treatment. EFORT Open Rev. 2018;3:335-46.

7. Käch K, Trentz O. Distraction spondylodesis of the sacrum in "vertical shear lesions" of the pelvis. Unfallchirurg. 1994;97:2838.

8. Brouwers L, Lansink KWW, de Jongh MAC. Quality of life after pelvic ring fractures: A cross-sectional study. Injury. 2018;49:812-18.

9. Van den Bosch EW, Van der Kleyn R, Hogervorst M, Van Vugt AB. Functional outcome of internal fixation for pelvic ring fractures. The Journal of trauma. 1999;47:365-71.

10. Zhao JX, Zhang LC, Su XY, Zhao Z, Zhao YP, Sun GF, Zhang LH, Tang PF. Early Experience with Reduction of Unstable Pelvic Fracture Using a Computer-Aided Reduction Frame. BioMed Research International. 2018;2018:7297635.

11. Chen K, Yao S, Yang F, Drepaul D, Telemacque D, Zhu F, Zeng L, Xiong Z, Sun T, Guo X. Minimally Invasive Screw Fixation of Unstable Pelvic Fractures Using the "Blunt End" Kirschner Wire Technique Assisted by 3D Printed External Template. Biomed Res Int. 2019;2019:1524908.

12. Peng $Y$, Zhang W, Zhang G, Wang X, Zhang S, Ma X, Tang P, Zhang L. Using the Starr Frame and Da Vinci surgery system for pelvic fracture and sacral nerve injury. J Orthop Surg Res. 2019;14:29.

13. Zhang LH, Zhao JX, Zhao Z, Su XY, Zhang LC, Zhao YP, Tang PF. Computer-aided pelvic reduction frame for anatomical closed reduction of unstable pelvic fractures. J Orthop Res. 2016;34:81-7.

14. Kanakaris NK, Angoules AG, Nikolaou VS, Kontakis G, Giannoudis PV. Treatment and outcomes of pelvic malunions and nonunions: a systematic review. Clin Orthop Relat Res. 2009;467:2112-24.

15. Lee KJ, Min BW, Oh GM, Lee SW. Surgical Correction of Pelvic Malunion and Nonunion. Clin Orthop Surg. 2015;7:396-401.

16. Bodin A, Roussouly P. Sacral and pelvic osteotomies for correction of spinal deformities. Eur Spine J. 2015;24 Suppl 1:S72-82.

17. Keel MJ, Benneker LM, Siebenrock KA, Bastian JD. Less invasive lumbopelvic stabilization of posterior pelvic ring instability: technique and preliminary results. J Trauma. 2011;71:E62-70.

\section{Figures}



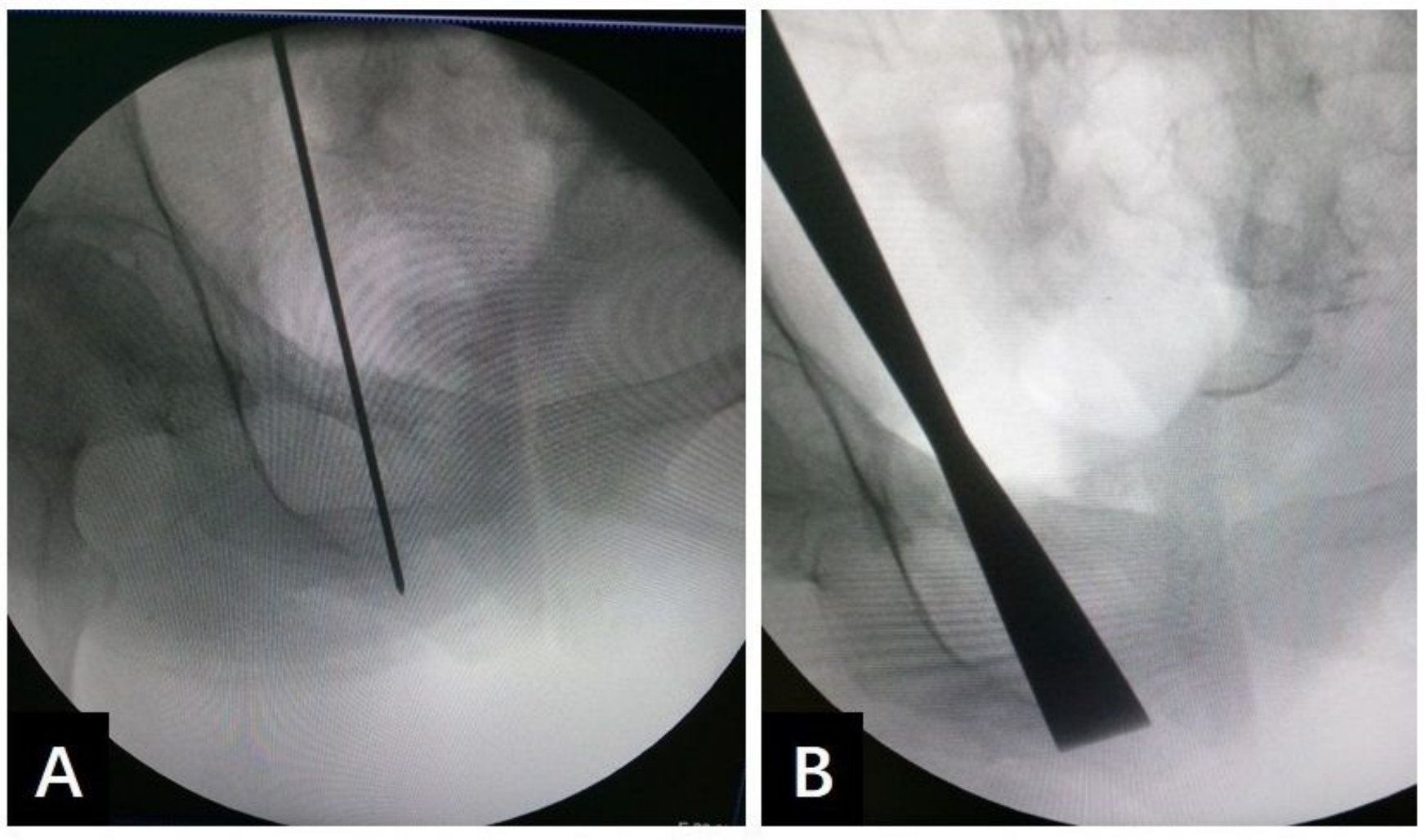

Figure 1

(A) Anteroposterior (AP) X-ray showed that the osteotomy line of the superior and inferior pubic rami was located with $2.0 \mathrm{~K}$-wires;

(B) bone was cut using an osteotome along the osteotomy line.
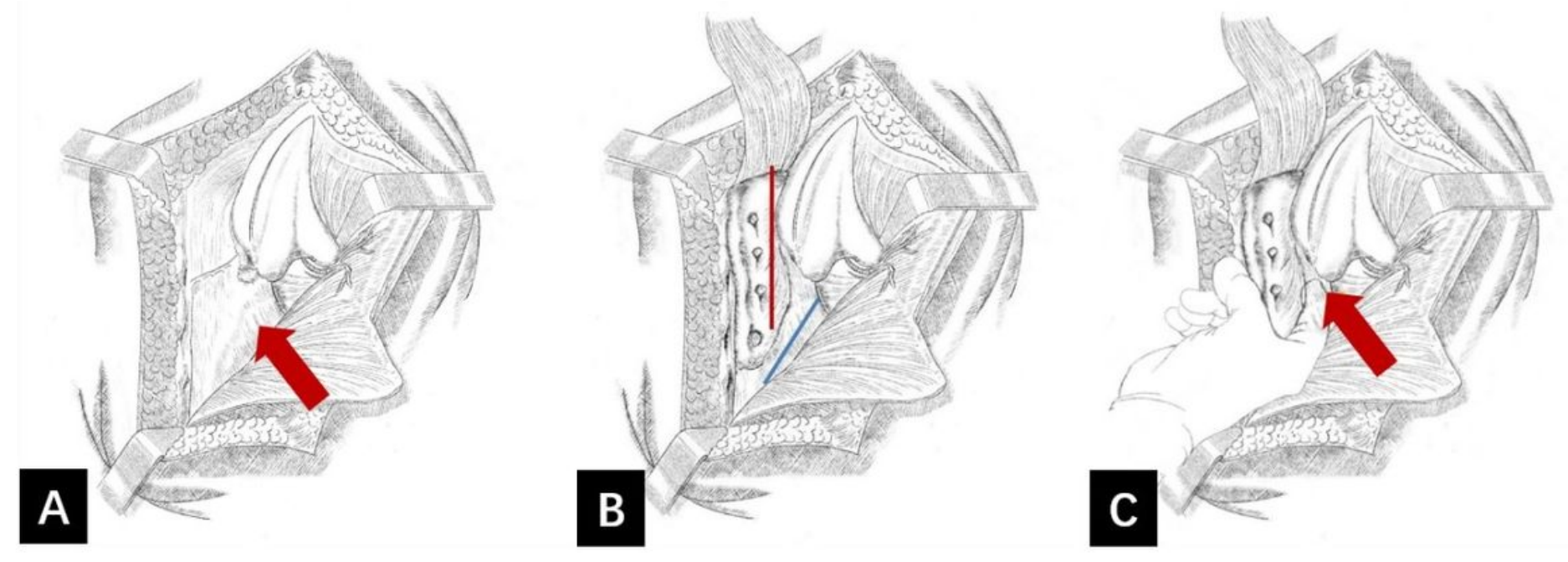

Figure 2

Schematic diagram for sacral osteotomy of a posterior pelvic ring; (A) the red arrow indicates the sacrotuberous ligament; (B) the red line indicates the location of sacral osteotomy and the blue line indicates the location of the incised sacrotuberous ligament; (C) the red arrow shows a schematic of the surgeon crossing the greater sciatic notch with the index finger to probe the anterior surface of the sacrum. 

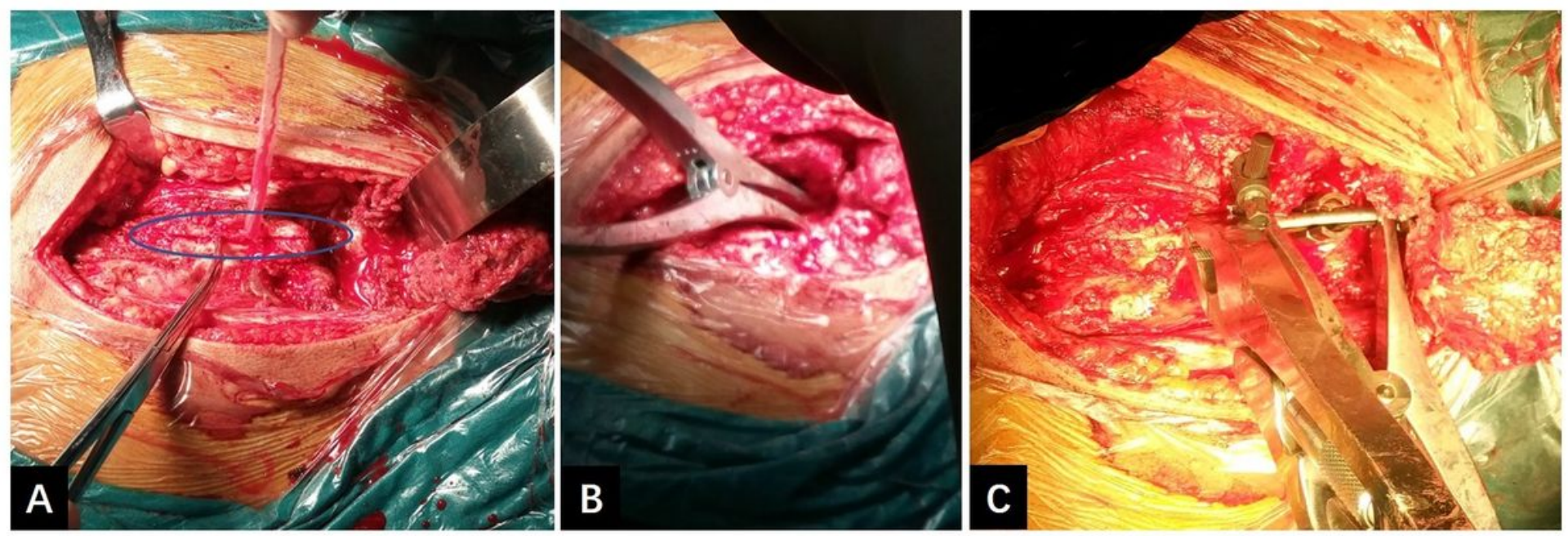

\section{Figure 3}

(A) The blue circle showed the sacral osteotomy line, which was located lateral to the sacral foramen; (B) the vertebral plate retractor was used to separate the bone to confirm complete cutting and disconnection of the sacrum; (C) distraction was performed between the pedicle screws (L4 and L5) and the iliac screw for the vertical displacement of a unilateral pelvis.
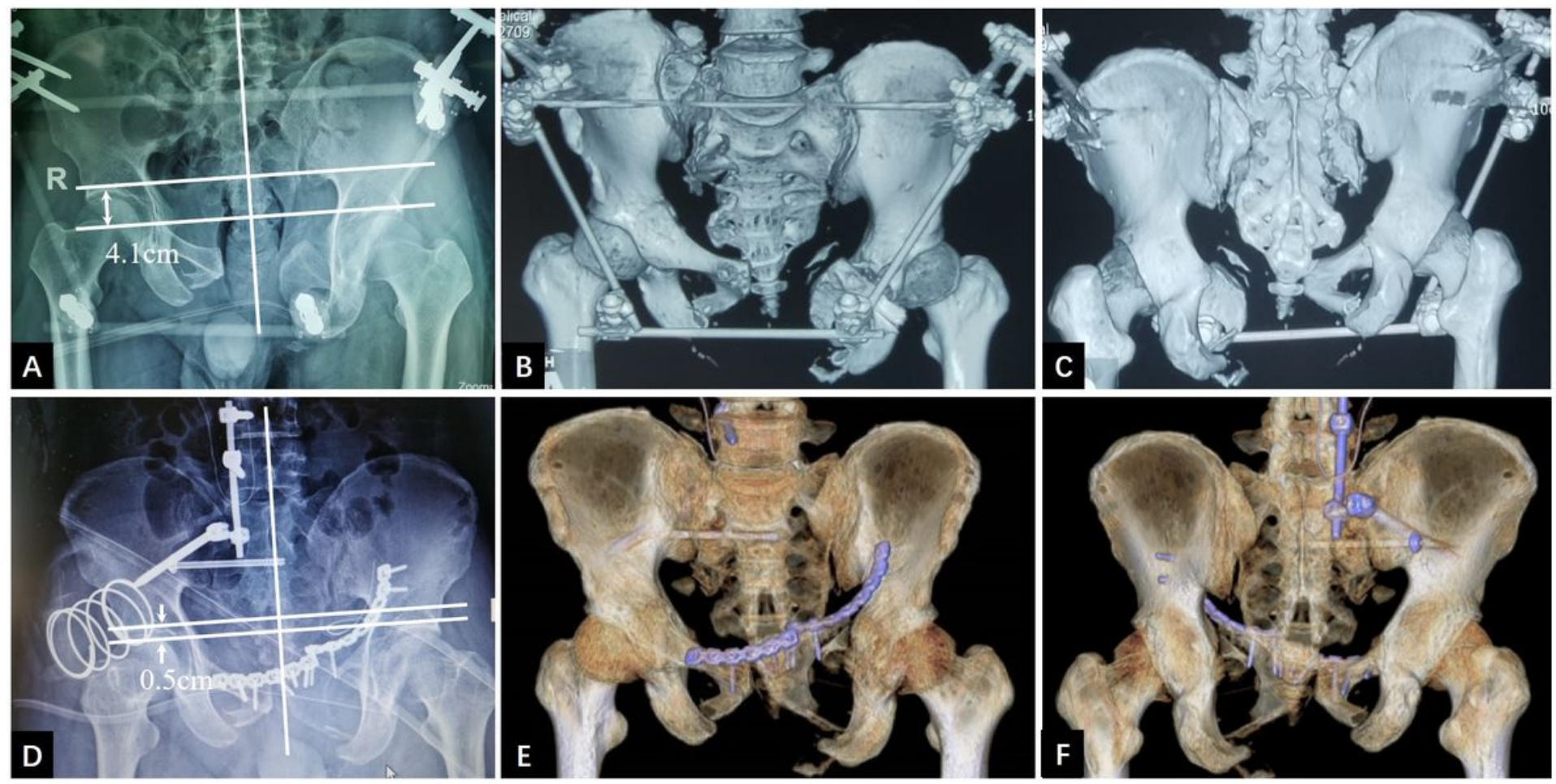

\section{Figure 4}

A 32-year-old male patient was performed in the prone-supine sequence; $(A)$ the preoperative AP X-ray showing significant vertical displacement of the right hemipelvis, with a displacement of $4.1 \mathrm{~cm} ;(\mathrm{B}, \mathrm{C})$ three-dimensional computed tomography (3D-CT) showed the pubic symphysis separation of the anterior pelvic ring and the malunion of the posterior pelvic ring; (D-F) the postoperative AP X-ray and the three-dimensional CT showed that the vertical displacement was reduced, with a residual displacement of $0.5 \mathrm{~cm}$. 

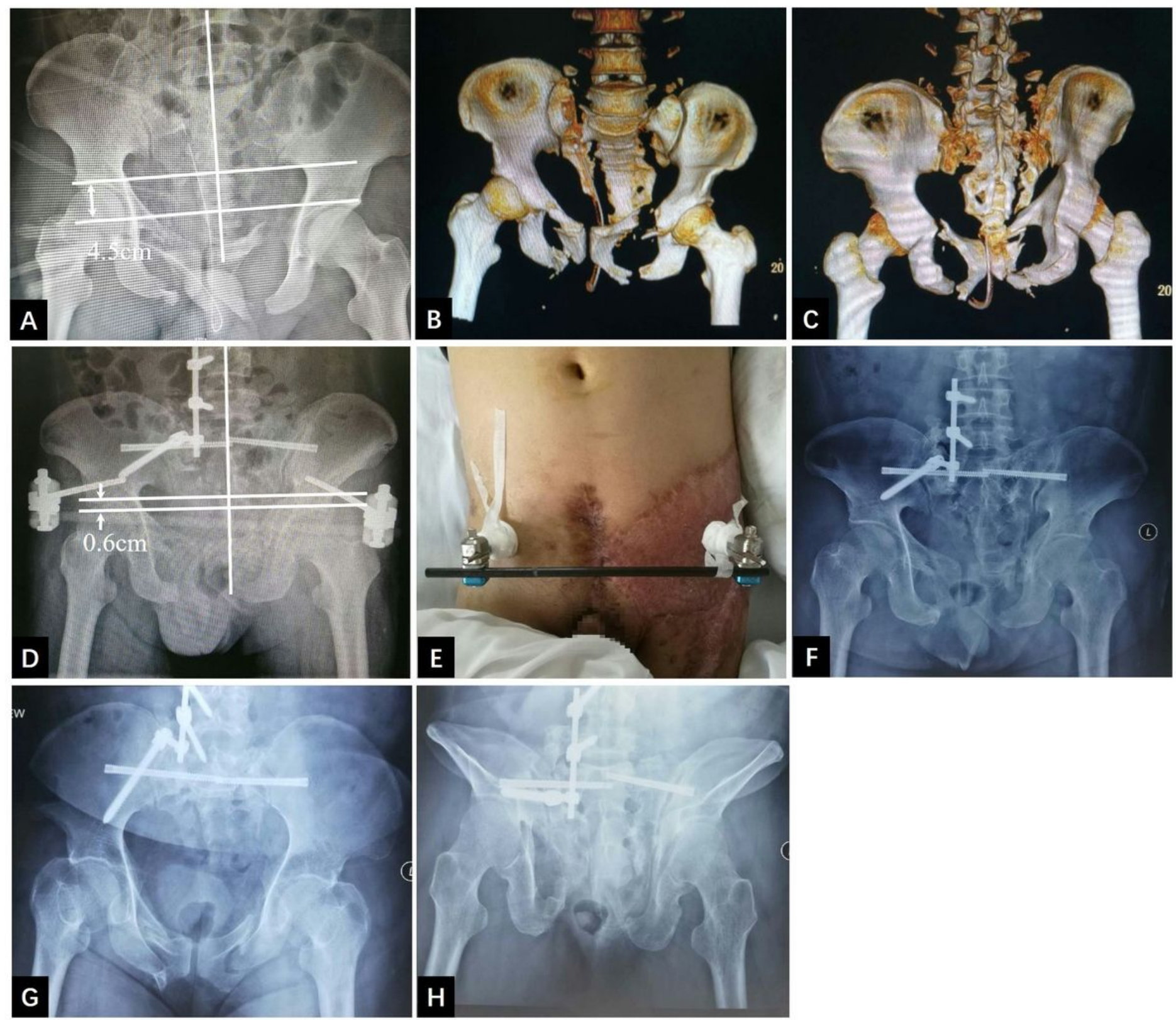

\section{Figure 5}

A 44-year-old male patient with type C3.3 pelvic fracture; (A-C) the preoperative AP X-ray and 3D-CT showed significant vertical displacement of a right hemipelvis, with a displacement of $4.5 \mathrm{~cm}$; (D) after osteotomy of the right sacrum, lumbopelvic distraction osteosynthesis, and bilateral sacroiliac screw fixation were performed, the vertical residual displacement of a unilateral pelvis was $0.6 \mathrm{~cm}$; $(E)$ due to the nonunion of pubic rami combined with severe third-degree burn scars in the left inguinal region, external fixator fixation of the anterior pelvic ring was performed; $(F-H)$ the AP, inlet, and outlet X-ray at the six-month follow-up showed no displacement of the fracture (the external fixator of the anterior pelvic ring was removed 3 months after surgery). 

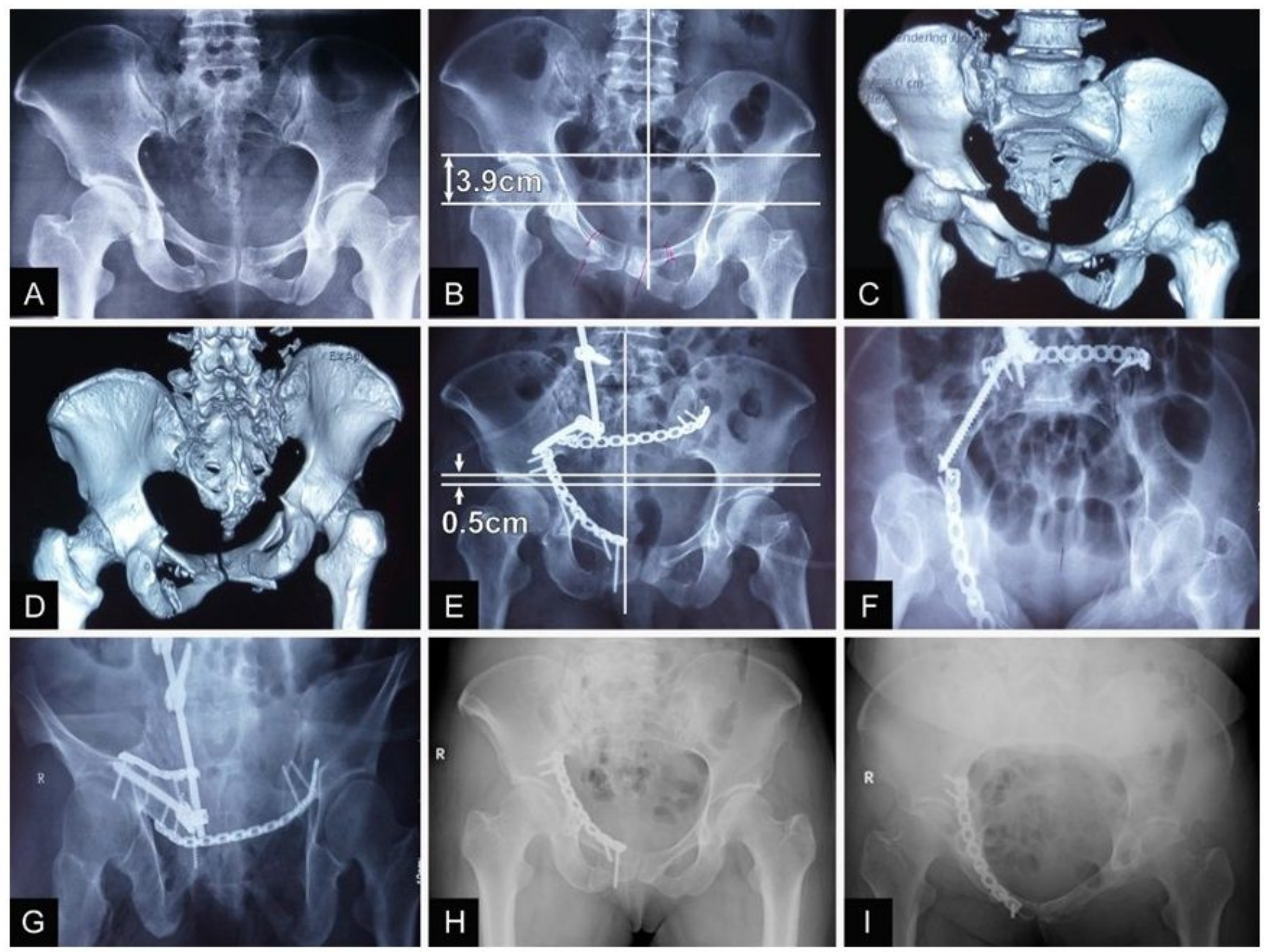

Figure 6

A 45-year-old female patient; (A) the AP X-ray at the time of injury showed the pelvic ring without obvious cranial displacement; (B) after 1 month of conservative treatment, the $3.9 \mathrm{~cm}$ cranial displacement of a unilateral pelvis was observed on an AP X-ray; (C, D) after the failure of reduction of femoral skeletal traction, the 3D-CT reconstruction showed a sacral malunion at 3 months; (E) postoperative AP X-ray showed that the cranial displacement was reduced with a residual displacement of $0.5 \mathrm{~cm} ;(F, G)$ inlet and outlet X-ray showed the displacement of hemipelvis had been reduced; $(\mathrm{H}, \mathrm{I})$ the pelvic radiographs acquired 15 months after the operation show that the fracture had healed and that the internal fixator of the posterior pelvic ring was removed. 